\title{
Implementing Community-Engaged Participatory Research Methods in a Study of Cree Women's Wellness: Describing Recruitment Processes and Outcomes
}

\author{
Nitya Khetarpal', Luwana Listener ${ }^{1}$, Richard T. Oster ${ }^{2}$, Sue Ross ${ }^{1}$, Cora \\ Voyageur $^{3}$
}

'Department of Obstetrics and Gynaecology, University of Alberta, Edmonton, Alberta

${ }^{2}$ Department of Agricultural, Food and Nutritional Science, University of Alberta, Edmonton, Alberta

${ }^{3}$ Department of Sociology, University of Calgary, Calgary Alberta

Corresponding author: nkhetarp@ualberta.ca

\section{ABSTRACT}

Background: In 2017, the Sohkitehew Group was funded to undertake research to identify wellness strategies adopted by mature women as they age in the rural Cree community of Maskwacis, Alberta. We describe our recruitment processes and outcomes for events from July 2017 to June 2018, the first phase of this research.

Methodology: Data gathered from minutes of 36 Sohkitehew Working Group and two Elders Advisory Committee meetings were used to identify recruitment strategies, event characteristics and recruitment outcomes for two large community events and three Sharing Circles.

Results:

1. Recruitment strategies: Strategies were similar for community events and Sharing Circles: event posters were displayed throughout Maskwacis, and advertisements were broadcast by Hawk Radio and appeared in Band newsletters.

2. Event Characteristics: Settings included a large community gymnasium for large events, and smaller community venues in different Bands for Sharing Circles. Traditional/cultural protocols were addressed by smudging meeting spaces, inviting community Elders to attend all events, and saying prayers. Healthy lunches were provided.

3. Event attendance: The two larger community events attracted 96 , and 37 participants, respectively. Sharing Circle attendance ranged from 8 to 23 participants.

Conclusion: Recruitment strategies succeeded for the Sohkitehew events in Maskwacis. Prior trusting and respectful relationships with the community established over several years provided a firm basis for this research. Successful recruitment efforts required time, planning, flexibility, and careful attention to culture and tradition to meet objectives to attract participants. Similar strategies may be successful in other rural Indigenous communities if tailored for the specific needs and expectations of individual communities.

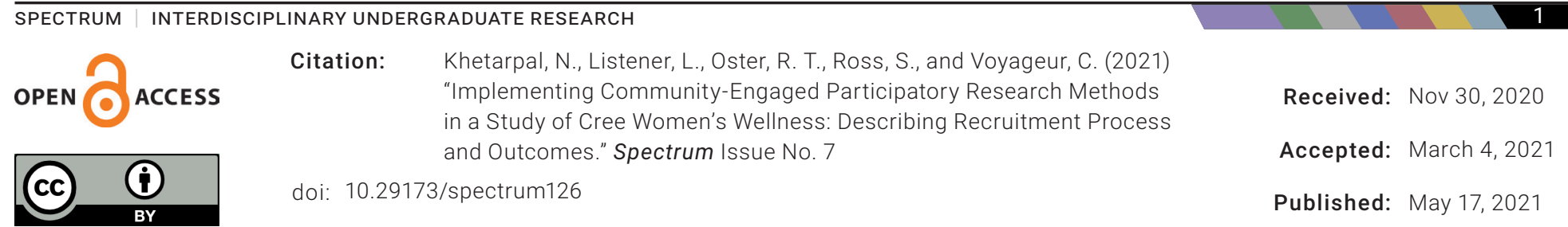




\section{Background}

The Sohkitehew (Strong Heart) Group has been undertaking mature women's health research since 2015 in Maskwacis, a large rural Cree community in Central Alberta. The community, situated on Treaty Six land, includes four Cree First Nation Bands (Samson, Ermineskin, Montana and Louis Bull), with a satellite community at Pigeon Lake that includes members from all of the Nations. The Maskwacis population consists of over 19,000 Cree people registered with the local Health Services.

The Sohkitehew Group itself has developed over six years, starting with preliminary research in 2015 exploring the Maskwacis women's experiences of menopause (Sydora, et al., 2021). The Group includes seven female Elders who represent each of the four Bands, professionals from Maskwacis Health Services, and academic researchers from the University of Alberta and University of Calgary. Dr. Cora Voyageur (Dene) is the Principal Investigator and has been involved throughout the project. The Group works in collaboration with other community members to undertake research. In 2017, Dr. Voyageur and the Sohkitehew Group were funded by the Canadian Institutes of Health Research (CIHR) to identify wellness and aging strategies adopted by mature Maskwacis women.

Recruitment for research can be difficult in Indigenous communities because of previous exploitation of Indigenous people by researchers, who collected samples or data from communities and yet the findings did not benefit the communities (Bull, 2010; Jull et al., 2018). Our research was carried out following the recommendations for doing research with Indigenous communities in Canada using the Tri-Council Policy Statement-2 chapter 9 (Canadian Institutes of Health Research, 2018) and First Nations and Indigenous Governing Council's Ownership, Control, Access and Possession Principles, or OCAP Principles (FNIGC., 2014). Our community-engaged participatory research methods were based on trusting partnerships between researchers and the community to carry out research for the benefit of the community. The research question was posed by the community, and methods considered cultural sensitivity, relevance, respectfulness, responsiveness, and reciprocity (Khodyakov, Mikesell \& Bromley, 2017). The research was planned to first benefit the community before findings were published (Wilson, 2008).

The research project's success in examining wellness strategies depended entirely upon community members attending community research events. Women's interest in a relevant research topic, accessibility, and willingness to take part made data collection possible. Our recruitment plans were carefully designed with community members to ensure that women felt they would benefit from taking time out of their busy days. Participants understood the purpose of the work and how any results would be useful to community members.

We therefore undertook this qualitative research study to explore and report the processes that were employed by the Sohkitehew Group to encourage participation and to explore the actual recruitment to inform our future recruitment activities.

\section{Objectives}

Our methodological research set out to describe the planning and recruitment processes we used to build trust with local women and to encourage them to participate in this community-engaged participatory research. The outcomes of our recruitment strategies were explored in terms of numbers of participants who joined research events held from 1 July 2017 to 30 June 2018, the first phase of our research about aging and wellness.

The findings of this research - descriptions and reflections about our recruitment efforts - can enhance both our own future community-engaged participatory research and help other researchers to plan their own research and recruitment strategies. 


\section{Methodology}

This retrospective research study collected data from all Working Group and Elders Advisory Committee meetings from 1 July 2017 to 30 June 2018. This 12-month period included different types of events, with two large community events, as well as three Aging Wellness Sharing Circles.

\section{Planning the community events}

Planning of the community events was carried out by two Sohkitehew groups, the Working Group and the Elders Advisory Committee. The Working Group consists of two University of Alberta researchers: research assistant Luwana Listener, a community member living in Maskwacis; and health researcher Sue Ross who has worked in Maskwacis since 2015. The Working Group met weekly in person or by phone. The Elders Advisory Committee consists of the seven Sohkitehew Group Elders and is joined by researchers Listener and Ross. Elders Advisory Committee meetings were held in person. Listener took minutes of all meetings. For this research, we used data collected from the meeting minutes of the Working Group and Elders Advisory Committee to identify information about event planning, recruitment strategies, administrative details, and event attendance. If necessary, the researchers individual notes (Listener and Ross) were used to expand on the meeting minutes.

\section{Community events}

The Sohkitehew Group held two types of community events - community feedback events and Aging Wellness Sharing Circles - that occurred during the 12-month data collection period for this retrospective review. The two community feedback events were held to present the results of our earlier research on menopause, and three Aging Wellness Sharing Circles were held as the first phase of data collection for our funded CIHR project. These events occurred within the time frame of 18 October 2017 to 26 June 2018.
- Community feedback events. The two large community events were held partly to provide feedback directly to the community about the results of Maskwacis research about menopause and partly to share information on aging well. The first event was a World Menopause Day Walk, which started with a walk held inside because of inclement weather, followed by lunch and talks about menopause and aging well. The second event was a Women's Wellness Workshop that included talks on a variety of wellness topics, including diet, exercise, mental health, and aging well. At both events we distributed menopause pamphlets developed by Maskwacis women (one for men and one for women/families) (Sydora, et al., 2021). Both events included lunch and prize draws.

- Aging Wellness Sharing Circles. Three community Aging Wellness Sharing Circles were planned as smaller events, similar to Sharing Circles described by others (Rothe, Ozegovic \& Carroll, 2009; Lavallée, 2009) to explore strategies that women use to age well. The discussions were guided using the four main elements of wellness: that is, physical, mental, emotional and spiritual wellness (Dell, 2015). Healthy lunches and prize draws were provided.

\section{Data collection}

Three main data elements contribute to this report:

- Recruitment processes. Text about planning and implementing recruitment processes was gathered from Working Group and Elders Advisory Committee minutes and researchers' notes. Then, it was grouped into categories that best described recruitment processes for the community feedback events and Sharing Circles held during the 12-month data collection period.

- Event characteristics. These were extracted from the Working Group meeting notes and advertising posters for the community events. The details included setting and type of venue, accessibility, cultural content, and any incentives used. 
- Recruitment outcomes. Event attendance was recorded at the end of each of the two community feedback events and the three Sharing Circles.

\section{Data management and analysis}

All data was entered into Excel spreadsheets for descriptive qualitative analysis, with each of the data elements explored separately.

- Recruitment processes. An Excel spreadsheet detailed recruitment efforts for each individual community event or Sharing Circle. Key phrases were extracted from meeting minutes and researchers' notes describing details of recruitment efforts. The extracts from each document were coded. From the coded text, the main areas of recruitment activity were grouped into themes

- Event characteristics. Details of event characteristics were tabulated for each individual community event or Sharing Circle. Event characteristics included the date, setting, type of venue, accessibility, cultural content, and any incentives used.

- Recruitment outcomes. Number of attendees was collated for each event.

\section{Ethics}

This study was approved by the University of Alberta Health Research Ethics Board (ID: Pro00076772, PI: Sue Ross) under the title "Increasing Mature Women's Wellness in an Indigenous Community: The Sohki Teyhew (Strong Heart) Group".

\section{Results}

We reviewed the minutes of all 36 Working Group meetings and both Elders Advisory Committee meetings held during the 12-month period that related specifically to planning the larger community events and Sharing Circles. Specific details of the recruitment processes are described. Event characteristics and recruitment outcomes are also provided (Table 1).

\section{Recruitment processes}

Although the purposes of the larger community events and Sharing Circles were different, the planning and recruitment processes were similar for both types of event.

- Community posters. Posters were placed on community noticeboards in Band offices and other public buildings such as local malls and health and wellness centres. These posters were designed to stand out from the usual community posters, and prominently described the topic and goals of a specific community event. The first event was a community Menopause Walk held on International Menopause Day followed by lunch and talks from several community leaders. The second event was a Wellness Workshop hosted jointly by Sohkitehew and Maskwacis Health Services, with a variety of health and wellness speakers. The goal of the Aging Wellness Sharing Circles was described on posters as being for attendees: "to join the discussion on aging well . . the goal of the Sharing Circle is to increase awareness and empower women of all ages, with the knowledge and tools needed to age healthy and well". The posters also stated clearly that the Sharing Circles were part of a research study. Community members were welcome to attend both types of events. Incentives such as door prizes and lunch were noted on the posters for both types of meetings.

- Hawk Radio. Radio is widely available in the community and is a popular source of up-to-date information about community events. Public meetings and other community events (including ours) are advertised several times each day, along with a variety of other local news, interviews and music. Unfortunately, the local radio station coverage does not extend to all parts of the Maskwacis community.

- Band newsletters. Newsletters are available online and in print, providing extensive information and advertisements for a wide range of community events. Our event posters were available in the appropriate newsletters. In addition, the two community events were attended by journalists from two of the Bands. They published articles in 
Table 1. Setting of Events, Planned Activities, and Attendance

\begin{tabular}{|c|c|c|c|}
\hline Event purpose, date & Setting & Planned activities & Attendees \\
\hline \multicolumn{4}{|c|}{ Community Feedback Events } \\
\hline $\begin{array}{l}\text { Maskwacis World Meno- } \\
\text { pause Day Walk, } \\
18 \text { October } 2017\end{array}$ & $\begin{array}{l}\text { Very large gym, halved using } \\
\text { a curtain, easy access }\end{array}$ & Community walk, speakers & 96 \\
\hline $\begin{array}{l}\text { Women's Wellness Work- } \\
\text { shop, } \\
28 \text { February } 2018\end{array}$ & $\begin{array}{l}\text { Very large gym, halved using } \\
\text { a curtain, easy access }\end{array}$ & $\begin{array}{l}\text { Speakers (wellness topics), } \\
\text { competitions }\end{array}$ & 37 \\
\hline \multicolumn{4}{|l|}{ Sharing Circles * } \\
\hline $\begin{array}{l}\text { Aging Wellness Sharing } \\
\text { Circle, } 10 \text { April } 2017\end{array}$ & $\begin{array}{l}\text { Recreation Centre large gym, } \\
\text { easy access }\end{array}$ & $\begin{array}{l}\text { Sharing Circle - guided } \\
\text { discussion }\end{array}$ & 23 (20 women, 3 men) \\
\hline $\begin{array}{l}\text { Aging Wellness Sharing } \\
\text { Circle, } 17 \text { May } 2017\end{array}$ & $\begin{array}{l}\text { Elders Centre, comfortable } \\
\text { medium-sized room, easy } \\
\text { access }\end{array}$ & $\begin{array}{l}\text { Sharing Circle - guided } \\
\text { discussion }\end{array}$ & 10 (9 women, 1 man) \\
\hline $\begin{array}{l}\text { Aging Wellness Sharing } \\
\text { Circle, } 26 \text { June } 2017\end{array}$ & $\begin{array}{l}\text { Large open hall, accessed by } \\
\text { steps/ramp }\end{array}$ & $\begin{array}{l}\text { Sharing Circle - guided } \\
\text { discussion }\end{array}$ & 8 (6 women, 2 men) \\
\hline
\end{tabular}

* Note: Sharing Circles were attended by 36 individual community members. Some Elders Advisory Committee members attended more than one of the Sharing Circles.

their newsletters specifically about these events in their newsletters, thus raising general awareness about our work.

\section{Event characteristics}

The events were held in community settings: two in individual Bands and one in the satellite community (Table 1).

- Settings and type of facility. There are limited spaces available for meetings and these are heavily used for community events, therefore compromises needed to be made to arrange dates and times of the Group's events. Our events were held in several different settings varying from large gyms to smaller meeting rooms. Some of the event participants were less mobile, so special consideration was made for ease of parking, building access, and availability of accessible washrooms. Although the larger gyms are not ideal settings because the sound does not carry well and they initially appear unwelcoming, they were chosen on the basis of availability and acceptability to the attendees. Each facility provided access to necessary equipment, such as tables and chairs. Different layouts were used for the different types of meeting - a banquet-style setting with tables of six to eight was used for the World Menopause Day lunch and for the Women's Wellness Workshop, while an open circle setting was used for the Sharing Circles. Tables were decorated by the researchers to be welcoming by using cheerful tablecloths and table decorations.

- Tradition and culture. It was important to address tradition and culture in ways that were respectful to the community members. Researcher Listener smudged meeting spaces before the events. Elders from the Group were able to attend all the events and were invited using protocol to provide welcoming prayers to start the meetings and before commencing lunch. Each Elder from the Group was given an honorarium in appreciation of their contribution of cultural knowledge and wisdom at every stage in event planning and throughout the events.

- Incentives. A variety of incentives were provided for all attendees. Coffee was available to welcome them at the start of meetings. A healthy lunch was provided by a local caterer. Prize draws, including gift cards from local stores and/or good food bags, 
were made at the end of each session. Other small items, such as pens and notebooks, were also provided. Our goal was to ensure that no one left empty-handed and would know that their input was appreciated by the research team.

\section{Event attendance}

Community workshops were well attended: the World Menopause Day Walk was attended by 96 individuals; the Aging Women's Wellness Workshop was attended by 37; and Sharing Circles were attended by 36 community members. Attendance at specific circles ranged from 8 to 23 people.

\section{Discussion}

This paper describes community-engaged participatory research (Khodyakov, Mikesell \& Bromley, 2017), in which Maskwacis and Pigeon Lake community members were involved in developing and taking part in research. The two community feedback sessions (World Menopause Day Walk and Aging Women's Wellness Workshop) were well attended and reported information about successful wellness strategies directly to community members, before publishing the findings more widely (Jacklin \& Kinoshameg, 2008; Wilson, 2008; Viscogliosi et al., 2017; Jull et al., 2018; Ninomiya et al., 2020). Participants were interested in learning about the outcomes of this Maskwacis research and how the findings were relevant to their community. Community members also attended research Sharing Circles that identified strategies for aging well (Rothe, Ozegovic \& Carroll, 2009; Lavallée, 2009). The Sharing Circles were more intimate events and therefore smaller recruitment was appropriate and expected.

Before we undertook this research, we had learned from our earlier research (Sydora et al., 2021) that community recruitment may fall below our expectations because of other unexpected community events or adverse weather. We had also learned that often, smaller meetings produced more valuable outcomes because those attending tended to be particularly interested in the topic. In addition, we had learned about the best ways to advertise and engage participants in the research we were doing, in the process establishing an "authentic research relationship" with the community (Bull, 2010). For all our events, the major strength was the Elders Advisory Committee which provided powerful input to all aspects of the work, including the topic and the design of workshops and community feedback sessions in line with others' recommendations (Bull, 2010; Ninomiya et al., 2020). The involvement of local health professionals speaking at our community events was valued by participants. As well, the input from researcher Listener herself a community member, ensures that we always consider the community's perspective about the research. Together, these activities demonstrate our commitment to Indigenous methods in our research (Fletcher, 2003; Wilson, 2008; Bull, 2010; Viscogliosi et al., 2017; Jull et al., 2018).

Of key importance to the conduct of the community feedback sessions and Sharing Circles was the attention paid to cultural practices (Fletcher, 2003; Jacklin \& Kinoshameg, 2008; Wilson, 2008; Bull, 2010; Jull et al., 2018), such as smudging the meeting spaces before the events and providing protocol for the Elders. The involvement of the Elders themselves is of great significance in developing this research. Their willingness to participate fully in group discussion, as well as to say prayers and bless the work is important, as highlighted by other researchers (Wilson, 2008; Bull, 2010; Viscogliosi et al., 2020). The Elders themselves clearly exemplify living life to the full, the community members' goal for this aging and wellness research.

We have not exhausted the options to enhance recruitment for research with the community. We have not yet used the individual Band Facebook pages to advertise events. We need to keep abreast of developments in communications strategies on reserve, because these are changing rapidly. Another significant issue in the community is the lack of transport for some women. We have not yet investigated providing transport because the community is so widely spread: rather we try to take our workshops to the people when we can. 
Table 2. Summary of Main Considerations in Planning Community Events Identified from Sohkitehew Working Group Minutes

\begin{tabular}{|c|c|}
\hline Considerations & Strategy, Practical issues \\
\hline $\begin{array}{l}\text { What value will your } \\
\text { event bring to the com- } \\
\text { munity? }\end{array}$ & $\begin{array}{l}\text { Consider this issue carefully from the community perspective. } \\
\text { This community has in the past experienced bad research practices, where community members } \\
\text { were recruited to research, but never learned about the results, and never (knowingly) received } \\
\text { any benefit from the research. Healing is still required to address these previous experiences. }\end{array}$ \\
\hline Consult Elders regularly & $\begin{array}{l}\text { Consultation with Elders is essential to make sure that your research is conducted according to } \\
\text { community practices. It is necessary to include Elders and provide honarariums. Traditional/cul- } \\
\text { tural protocol must be used when consulting Elders. } \\
\text { Remember that Elders are very busy people - do not overburden them. }\end{array}$ \\
\hline $\begin{array}{l}\text { Engage community } \\
\text { members in planning }\end{array}$ & $\begin{array}{l}\text { How to identify individuals? What value would community members feel through being involved? } \\
\text { Establish trusting relationships before starting the research. }\end{array}$ \\
\hline $\begin{array}{l}\text { Type of event best to } \\
\text { address purpose }\end{array}$ & What is the purpose of the meeting - is a smaller event or larger event best (and feasible)? \\
\hline Size of event & Smaller versus larger space needed, what facilities are necessary? \\
\hline $\begin{array}{l}\text { Identify possible } \\
\text { locations, availability, } \\
\text { accessibility, parking. }\end{array}$ & $\begin{array}{l}\text { Consider participant mobility limitations and other transport concerns when selecting venue as } \\
\text { some participants may be less mobile. }\end{array}$ \\
\hline Detailed planning needed & $\begin{array}{l}\text { Set-up of meeting space, food (snacks and/or catering), attractive layout, speakers and/or activi- } \\
\text { ties, accessibility of the venue. } \\
\text { Speakers may need to be booked well in advance. }\end{array}$ \\
\hline Timing of event & $\begin{array}{l}\text { Who are you hoping to attract, your target audience? What timing may be most attractive? } \\
\text { For working people, lunch time may be best. Mothers may be unavailable outside school hours. } \\
\text { Transport may be an issue. }\end{array}$ \\
\hline $\begin{array}{l}\text { Why would community } \\
\text { members attend your } \\
\text { event? }\end{array}$ & $\begin{array}{l}\text { Communication is essential - use every possible method, eg. posters, adverts, radio, personal } \\
\text { contacts, word of mouth. } \\
\text { Attendance must be easy and attractive for community members. Consider accessibility. Men- } \\
\text { tion food, prize draws, other attractions. } \\
\text { Make sure to thank attendees for their time and contribution. }\end{array}$ \\
\hline Cancellation of meeting & $\begin{array}{l}\text { Community meetings are sometimes cancelled at short notice out of the organiser's control. If } \\
\text { so, donate food/catering in the community. } \\
\text { Usual reasons for cancellation: wakes/funerals take precedent over research events, severe } \\
\text { weather or mechanical breakdown can cause closure of event locations. }\end{array}$ \\
\hline $\begin{array}{l}\text { Other community events } \\
\text { may be in conflict }\end{array}$ & $\begin{array}{l}\text { Attendance may be less than expected because of another community meeting occurring at the } \\
\text { same time. } \\
\text { Smaller meetings often prove to be more productive. It is always beneficial to proceed. }\end{array}$ \\
\hline
\end{tabular}

The outstanding attendance at the World Menopause Day Walk was uncharacteristically high compared to any of our other events. This was a result of a Band financial meeting being held in the other half of the gym at the same time as the walk. This financial meeting, which we did not know about until the morning of the walk, was attended by a predominantly male audience and finished shortly before our lunch started. Therefore, many of the finance meeting attendees joined our menopause lunch and prize draws and stayed to listen to the guest speakers who talked about our menopause and wellness research. This meant our research findings were shared with an audience we do not generally reach. Such unexpected changes of plans can produce benefits for our research, as long as we are flexible and respectful of community.

From our research, we have assembled details of the key factors we found important for planning our 
research events in Maskwacis (Table 2). These factors may be useful for other researchers planning similar community-based research: the importance of Elders in planning and participating in events, the value of cultural and traditional practices, the purpose and value of the event for community members, and detailed planning (size of event, identifying suitable venues, providing hospitality).

\section{Conclusion}

Recruitment to our community feedback and research events was appropriate for the different types of event. In particular, the Sharing Circles were designed to respond directly to issues identified by the Elders Advisory Committee and addressed the needs of the community participants. Importantly, knowledge translation events were planned with the Elders Advisory Committee as part of the research to make sure that the wider community benefited first from the knowledge generated by community members about menopause and aging well before publication in the research literature, as recommended by others (Fletcher, 2003; Jacklin \& Kinoshameg, 2008; Wilson, 2008; Bull, 2010; Jull, et al., 2018; Viscogliosi et al., 2020). Similar strategies may be successful in other rural Indigenous communities but must be tailored for specific cultures, needs and expectations of each individual community.

\section{Acknowledgements}

We are grateful for the support and wisdom of the Sohkitehew Elders Advisory Committee: Margaret Montour, Mary Moonias, Rosie Roan, Phyllis Potts, Rose Makinaw, Lynda Omeasoo, and Yvonne Saddleback. Without their guidance, none of the Sohkitehew research would be possible.

Our work has been made possible by the community members of Maskwacis who have given their time and shared their experiences at Sohkitehew meetings.

This research is supported by a grant awarded by the Institute for Indigenous People's Health, Canadian Institutes of Health Research (CIHR).

Sue Ross is funded by the generosity of the Alberta Women's Health Foundation through the Women and Children's Health Research Institute. 


\section{Works Cited}

Bull, J. R. (2010). Research with Aboriginal peoples: authentic relationships as a precursor to ethical research. J Empir Res Hum Res Ethics, 5(4), 13-22. https://doi.org/10.1525/jer.2010.5.4.13

Canadian Institutes of Health Research, Natural Sciences and Engineering Research Council of Canada, and Social Sciences and Humanities Research Council of Canada, Tri-Council Policy Statement (TCPS 2): Ethical Conduct for Research Involving Humans, December 2018. https://ethics.gc.ca/ eng/policy-politique_tcps2-eptc2_2018.html

Dell, C. A., Dell, D., Dumont, J., Fornssler, B., Hall, L., \& Hopkins, C. (2015). Connecting with culture: Growing our wellness. Facilitators' Handbook. Saskatoon, SK: University of Saskatchewan, Research Chair in Substance Abuse. https://cyfn.ca/wp-content/uploads/2016/10/Growing-Wellness-Facilitators_ Manual_DIGITAL_FILE.pdf

Fletcher, C. (2003). Community-based participatory research relationships with Aboriginal communities in Canada: An overview of context and process. A Journal of Aboriginal and Indigenous Community Health, 1(1).

First Nations Information Governance Centre (FNIGC). Ownership, Control, Access and Possession (OCAP ${ }^{T M}$ ): The Path to First Nations Information Governance. May 2014. https://fnigc.ca/ocap-training/

Jacklin, K., \& Kinoshameg, P. (2008). Developing a participatory Aboriginal health research project: "Only if it's going to mean something". J Empir Res Hum Res Ethics, 3(2), 53-67. https://doi.org/10.1525/ jer.2008.3.2.53

Jull J., Ninomiya, M. M., Compton I., \& Picard A. (2018). Fostering the conduct of ethical and equitable research practices: the imperative for integrated knowledge translation in research conduted by and with indigenous community members. Res Involv Engagem, 4, 45. https:// doi.org/10.1186/ s40900-018-0131-1

Khodyakov D, Mikesell L \& Bromley E. (2017). Trust and the ethical conduct of community-engaged research. Eur J Pers Cent Healthc,5(4),522-526. https://doi.org/10.5750/ejpch.v5i4.1263

Lavallée, L. F. (2009). Practical application of an Indigenous research framework and two qualitative Indigenous research methods: Sharing Circles and Anishnaabe symbol-based reflection. International Journal of Qualitative Methods, 8(1), 21-40. https://doi.org/10.1177\%2F160940690900800103

Ninomiya, M. M., George, N. P., George, J., Linklater, R., Bull, J., Plain, S., Graham K., Bernards S., Peach L., Stergiopoulos V., Kurdyak P., McKinley G., Donnelly P., \& Wells, S. (2020). A community-driven and evidence-based approach to developing mental wellness strategies in First Nations: a program protocol. Res Involv Engagem, 6, 5. https://doi: 10.1186/s40900-020-0176-9

Rothe, J. P., Ozegovic, D., \& Carroll, L. J. (2009). Innovation in qualitative interviews: “Sharing Circles" in a First Nations community. Inj Prev, 15(5), 334-340. http://dx.doi.org/10.1136/ip.2008.021261

Sydora, B.C., Graham, B., Oster, R.T., \& Ross, S. Menopause experience in First Nations women and initiatives for menopause symptom awareness; a community-based participatory research approach [Manuscript submitted for publication]. BMC Women's Health Research.

Viscogliosi, C., Asselin, H., Basile, S., Couturier, Y., Drolet, M. J., Gagnon, D., Torrie, K., \& Levasseur, M. (2017). A scoping review protocol on social participation of indigenous elders, intergenerational solidarity and their influence on individual and community wellness. BMJ Open, 7(5), e015931. https://doi.org/10.1136/bmjopen-2017-015931

Viscogliosi, C., Asselin, H., Basile, S., Borwick, K., Couturier, Y., Drolet, M-J., Gagnon, D., Obradovic, N., Torrie, J., Zhou, J., Levasseur, M. (2020). Importance of Indigenous elders' contributions to individual and community wellness: results from a scoping review on social participation and intergenerational 
solidarity. Can J Public Health, 111, 667-681. https://doi.org/10.17269/s41997-019-00292-3 Wilson, S. (2008). Research is ceremony: Indigenous research methods. Fernwood Publishing. 